\title{
Analisis Tingkat Keaktifan Pengelolaan Hutan Desa Labbo
}

\author{
Andi Batari ${ }^{1,}{ }^{*}$, Yusran Yusran ${ }^{2}$, Muhammad Alif K.Sahide ${ }^{2}$ \\ ${ }^{1}$ Mahasiswa Fakultas Kehutanan Universitas Hasanuddin, Makassar \\ 2 Staf Pengajar Fakultas Kehutanan Universitas Hasanuddin \\ *E-mail: andibatari006@gmail.com
}

\begin{abstract}
The purpose of the research to analysis forest management level activity at Desa Labbo intens to Production, Distribution and Local Institution with the comparison of achievement program in the establishment formal document RKHD (Rencana Kerja Hutan Desa), RTHD (Rencana Tahunan Hutan Desa), village regulation 02 of 2010 and guideline of 01/BMDS- GT/LB/KTB/I/2010 based on the reality, and to determine forest management Desa Labbo Categorized by active management or hollow management to known stakeholder/actor get benefit or harmed by the hollow management system. Research will be held on Januari 2017 at Desa Labbo Kecamatan Tompobolu,Kabupaten Bantaeng of South Sulawesi. This Research use the snowball sampling system(triangulasy system). Snowball sampling like as snowball was rolling in the end was bigger, like as collect information the research. Interview at the respondent to get accuracy information and verify to get validity data. Research Object are Formal Document Establishment of Implementation Planning in the Document with comparison the real condition. Result research showing forest management system Desa Labbo Categorized active management will be realization 25,19\%, not realization $41,20 \%$, that counting can not to compare with high and low, important or not with the unsure (production, distribution,institution), because the unsure of research will be get the same research. About the actor will be get benefit at the hollow management status at forest village Labbo is head of village but the Actor will be get Hermed by active management system is balang institute.
\end{abstract}

Keywords: forest management; forest village; Desa Labbo; active management; hollow management DOI: $10.24259 / j h m . v 9 i 1.1837$

\section{PENDAHULUAN}

Berdasarkan konsep pengelolaan hutan yang lestari, Kementrian Kehutanan telah memberikan akses kepada masyarakat desa untuk mengelola kawasan hutan secara legal, salah satunya adalah skema hutan desa dengan hak akses pengelolaan selama 35 tahun (Nurdiansyah, 2013; Santosa dkk, 2011; Supratman dan Sahide, 2010 ; Suwarti dkk, 2015). Di Sulawesi Selatan, dengan berdasarkan Surat Keputusan Menteri Kehutanan (sekarang Kementrian Lingkungan Hidup dan Kehutanan atau KLHK) No.55/MANHUT-II/2010 telah menetapkan Hutan Desa di Kabupaten Bantaeng dengan luasan 342 ha terletak dalam wilayah administrasi Desa Labbo, Kecamatan Tompobulu, Kabupaten Bantaeng. (Ningrum, 2011; Supratman, 2012; Yusran, 2012; Muin dan Hapsari, 2014).

Setelah pemerintah daerah Bantaeng mendapatkan hak legal dalam mengelola kawasan hutan desa khususnya Hutan Desa Labbo sebagaimana SK Menteri Kehutanan No. 55/MENHUT-II/2010 dan setelah penetapan Hutan Desa Labbo melalui Surat Keputusan Gubernur Sulawesi Selatan nomor 3805/XI/TH 2010, maka selanjutnya pemerintah melimpahkan kewenangannya kepada lembaga desa yakni BUMDes Ganting, dengan agenda perencaaan pengelolaan hutan desa yang harus dituliskan melalui dokumen formal atau dokumen Rencana Kerja Hutan Desa (RKHD), Peraturan Desa Labbo, Rencana Tahunan Hutan Desa (RTHD), dan Pedoman Pengelolaan BUMDes Labbo yang menjadi acuan bagi pelaksanaan pengelolaan hutan (Supratman, 2012; Supratman dan Sahide, 2013).

Penelitian ini menilai keaktifan pengelolaan hutan tersebut dengan membandingkan perencanaan dan implementasinya pada tiga isu awal yakni unit usaha bisnis hutan desa yakni komponen produksi, distribusi, 
dan institusi. Oleh karena itu, akan dilakukan penelitian mengenai tingkat keaktifan pengelolaan hutan desa labbo pada konteks perencanaan produksi, distribusi, dan institusi lokal disetiap unit bisnis pengelolaan Hutan Desa Labbo untuk melihat sejauh mana RKHD (Rencana Kerja Hutan Desa), Peraturan Desa Labbo, Rencana Tahunan Hutan Desa (RTHD), dan Pedoman Pengelolaan BUMDes Labbo terealisasi dalam enam tahun terakhir dan untuk melihat sejauh mana active management pengelolaan Hutan Desa Labbo eksis dilapangan serta mengidentifikasi aktor yang mendapat keuntungan pada pengelolaan hollow management dan aktor yang dirugikan pada pengelolaan active management.

\section{METODOLOGI PENELITIAN}

Penelitian ini dilaksanakan pada bulan Januari 2017, yang bertempat di Desa Labbo Kecamatan Tompobulu Kabupaten Bantaeng Provinsi Sulawesi Selatan. Objek pada penelitian ini adalah menganalisis perencanaan unit bisnis pengelolaan Hutan Desa Labbo baik dari segi hasil hutan non kayu dan jasa lingkungan, dan performansi antara dokumen formal perencanaan Hutan Desa Labbo dan realisasinya di lapangan. Adapun jenis data yang dibutuhkan dalam penelitian ini berupa:

\subsection{Data Primer}

Data primer diperoleh melalui data hasil wawancara terfokus dengan pengelola Hutan Desa terkait. Hasil yang diperoleh berupa data kemudian dianalisis dengan menggunakan metode triangulasi (Bachri, 2010) serta data yang ditemukan melalui wawancara akan diverifikasi melalui observasi.

\subsection{Data Sekunder}

Data sekunder diperoleh melalui lembaga/instansi yang terkait dan jurnal hasil penelitian. Data sekunder tersebut meliputi keadaan umum lokasi, peraturan-peraturan pengelolaan hutan desa, serta data unit usaha yang dikelola oleh BUMDes.

\subsection{Wawancara}

Wawancara dilakukan untuk mendapatkan informasi terkait pengimplementasian dokumen yang telah terlaksana ataupun belum serta alasannya. Narasumber, seseorang yang akan dimintai keterangan terkait penelitian. Ada dua kategori narasumber yang akan di wawancai. Yang pertama adalah pihak-pihak yang terkait dengan penyusunan dokumen antara lain konsultan, LSM lokal, komisaris dan Direktur BUMDes. Yang kedua adalah pihak-pihak yang mengimplementasikan secara langsung dokumen tersebut antara lain adalah Direktur BUMDes dan seluruh anggota BUMDes (kelompok tani hutan) yang terkait dengan Hutan Desa Labbo. Khusus untuk kategori narasumber kedua ini, peneliti akan menerapkan snowball sampling (Nurdiani, 2014) yang artinya kami akan berhenti mencari informasi ketika tidak ada lagi informasi yang baru.

\subsection{Observasi}

Observasi adalah metode pengamatan yang dilakukan secara langsung dilapangan (Nasution, 2001). Penelitian ini melakukan pengamatan terhadap :

1. Aktivitas pengelolaan Hutan Desa dengan menilai perencanaan yang dijanjikan oleh dokumen formal dengan implementasinya, apakah hutan desa tersebut terkategorisasi sebagai active management (Staphans \& Ruth, 2005; Priantara, 2012) atau hollow management (Munks dkk, 2009; Smith \& Lindenmayer, 1988). Isu awal yang diamati adalah produksi, distribusi, dan institusi lokal. Isu awal ini dapat berkembang sesuai dengan temuan sampel yang diobservasi. 
2. Menganalisis kebijakan institusi lokal Hutan Desa yaitu BUMDes Ganting dalam menindaklanjuti dokumen yang belum terimplementasi.

3. Menganalisis implementasi dokumen formal mengenai konteks Produksi, Distribusi dan Institusi Lokal Hutan Desa Labbo.

4. Mengamati siapa saja yang mendapatkan keuntungan pada pengelolaan hollow management dan siapa pula yang dirugikan pada pengelolaan active management

Data primer dan data sekunder diolah dengan analisis dokumen (content analysis) merupakan sebuah metode kajian yang berlandaskan teori kajian sebagai sumber gagasan baru dan untuk meningkatkan kepahaman kajian penelitian yang berbentuk teks (Raditya, 2012). Dokumen yang dimaksud dalam hal ini adalah dokumen RKHD atau dokumen lainnya yang terkait perencanaan pengelolaan Hutan Desa Labbo yang telah berjalan (active management).

\section{HASIL DAN PEMBAHASAN}

\subsection{Aspek Produksi}

Gambar di bawah ini menunjukkan hasil persentase tingkat realisasi kegiatan pengelolaan Hutan Desa dalam konteks Produksi pada dokumen Peraturan Desa Bab VI pasal 10 dan pasal 10 ayat (2), Rencana Kerja Hutan Desa Bab III, Rencana Tahunan Hutan Desa halaman 10-17 dan Pedoman Pengelolaan Hutan Desa Labbo.

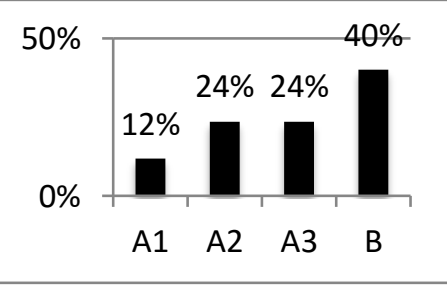

Gambar 1. Persentase tingkat realisasi kegiatan pengelolaan Hutan Desa dalam konteks produksi keterangan :

A1 : terealisasi (perdes Bab VII pasal 10)

A2 : terealisasi (RKHD dan RTHD)

A3 : terealisasi (Perdes dan Pedoman Pengelolaan HD Labbo)

B : tidak terealisasi dari Keempat dokumen

\subsection{Aspek Distribusi}

Gambar dibawah ini menunjukkan hasil persentase tingkat realisasi kegiatan pengelolaan Hutan Desa dalam konteks Distribusi dari dokumen Rencana Kerja Hutan desa pada halaman 14-15 dan dokumen Rencana Tahunan Hutan Desa.

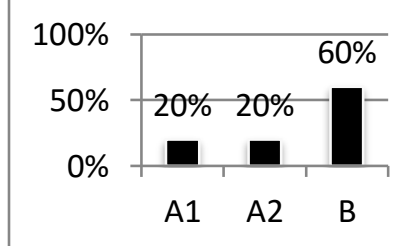

Gambar 2. Persentase tingkat realisasi kegiatan pengelolaan Hutan Desa dalam konteks Distribusi 
Keterangan :

A1 : terealisasi (RKHD)

A2 : terealisasi (RTHD)

B : tidak terealisasi dari Kedua dokumen

\subsection{Aspek Institusi Lokal}

Gambar dibawah ini menunjukkan hasil Persentase tingkat realisasi kegiatan pengelolaan Hutan Desa dalam konteks Institusi Lokal dalam dokumen Peraturan Desa dan Pedoman Pengelolaan BUMDes.

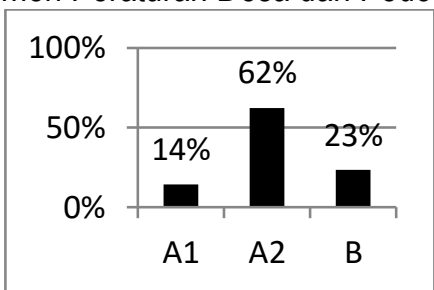

Gambar 3. Persentase tingkat realisasi kegiatan pengelolaan Hutan Desa dalam konteks institusi Keterangan :

A1 : terealisasi (Perdes )

A2 : terealisasi (Pedoman Pengelolaan)

$B$ : tidak terealisasi dari Kedua dokumen

\subsection{Analisa Keaktifan}

Dari hasil analisa dalam menilai kegiatan pengelolaan hutan desa, terdapat beberapa kriteria yang dapat dijadikan landasan dalam mengelola hutan dengan baik menurut Yadav dkk (2003). Kriteria ini dapat dijadikan acuan untuk membandingkan keadaan yang sebenarnya di lapangan.

Tabel 1. Hasil analisa keaktifan pengelolaan Hutan Desa Labbo

\begin{tabular}{|c|c|c|c|}
\hline No & Active Forest Management & Hasil Observasi Lapangan & Alasan \\
\hline 1 & $\begin{array}{l}\text { Pengelolaan hutan yang baik } \\
\text { untuk dimaksimalkan } \\
\text { kegunaannya }\end{array}$ & $\begin{array}{l}\text { Dilakukan penanaman kopi } \\
\text { secara agroforestry }\end{array}$ & $\begin{array}{l}\text { Potensi hutan desa yang } \\
\text { termanfaatkan yaitu pada jasa } \\
\text { lingkungan dan agroforestry } \\
\text { kopi. }\end{array}$ \\
\hline 2 & $\begin{array}{l}\text { Pengguna mampu membuat } \\
\text { perencanaan pengelolaan sesuai } \\
\text { dengan kebutuhan yang } \\
\text { diperlukan }\end{array}$ & $\begin{array}{l}\text { Perencanaan yang dibuat pada } \\
\text { saat pengusulan hutan desa } \\
\text { sangat baik karena } \\
\text { menyesuaikan dengan kondisi } \\
\text { dilapangan. }\end{array}$ & $\begin{array}{l}\text { Perencanaan pembagian blok } \\
\text { kawasan hutan desa telah } \\
\text { terealisasi. Terdapat } 3 \text { blok } \\
\text { yang telah dibagi dalam } \\
\text { pengelolaan yaitu blok Batu } \\
\text { Lappa dan Pattiroang dan blok } \\
\text { Saro Anging. }\end{array}$ \\
\hline 3 & $\begin{array}{l}\text { Sistem manajemen yang } \\
\text { bijaksana dalam pendirian blok } \\
\text { yang berotasi }\end{array}$ & $\begin{array}{l}\text { Sistem manejemen yang sejauh } \\
\text { ini baik. Namun pada } \\
\text { pengaplikasian dilapangan, terjadi } \\
\text { zonasi blok yang berbeda dengan } \\
\text { kondisi lapangan. }\end{array}$ & $\begin{array}{l}\text { Desa Bontotapalang masuk } \\
\text { kedalam areal kerja hutan desa } \\
\text { Labbo. }\end{array}$ \\
\hline
\end{tabular}




\begin{tabular}{|c|c|c|c|}
\hline 4 & $\begin{array}{l}\text { Dilakukan penanaman untuk } \\
\text { rehabilitasi lahan terbuka }\end{array}$ & $\begin{array}{l}\text { Belum ada penanaman untuk } \\
\text { rehabilitasi mengingat status } \\
\text { Hutan Desa Labbo adalah hutan } \\
\text { lindung. }\end{array}$ & $\begin{array}{l}\text { Status Hutan Desa Labbo yaitu } \\
\text { hutan lindung. Sehingga tidak } \\
\text { ada motivasi untuk melakukan } \\
\text { penanaman. Selain itu, } \\
\text { penutupan tajuk nya juga } \\
\text { masih sangat bagus. }\end{array}$ \\
\hline 5 & $\begin{array}{l}\text { Memberi perlakuan (thinning, } \\
\text { pruning \& cleaning) untuk } \\
\text { regenerasi spesies yang di } \\
\text { inginkan }\end{array}$ & $\begin{array}{l}\text { Tidak ada perlakuan (thinning, } \\
\text { pruning \& cleaning) dalam } \\
\text { kawasan hutan lindung }\end{array}$ & $\begin{array}{l}\text { Status hutan desa Labbo yaitu } \\
\text { hutan lindung sehingga tidak } \\
\text { ada aktifitas perlakuan } \\
\text { (thinning, pruning \& cleaning) } \\
\text { di dalamnya. }\end{array}$ \\
\hline 6 & $\begin{array}{l}\text { Rasional pemanfaatan hasil } \\
\text { hutan : ekstraksi dan } \\
\text { pemanfaatan kayu cacat, } \\
\text { jatuh/tumbang dan mati untuk } \\
\text { menghasilkan kayu bakar dll }\end{array}$ & $\begin{array}{l}\text { Tidak ada kegiatan ekstraksi dan } \\
\text { pemanfaatan kayu tumbang. }\end{array}$ & $\begin{array}{l}\text { Berdasar pada aturan bahwa } \\
\text { dilarang mengambil pohon } \\
\text { yang tumbang (pasal } 13 \text { ayat } 6 \\
\text { pada pedoman pengelolaan } \\
\text { hutan desa). }\end{array}$ \\
\hline 7 & $\begin{array}{l}\text { Melakukan pembibitan terhadap } \\
\text { spesies tertentu (madu) }\end{array}$ & $\begin{array}{l}\text { Pembibitan (madu) dilakukan } \\
\text { diluar kawasan hutan desa }\end{array}$ & $\begin{array}{l}\text { Status hutan desa Labbo } \\
\text { merupakan hutan lindung }\end{array}$ \\
\hline 8 & $\begin{array}{l}\text { Menjual hasil kayu yang } \\
\text { berlimpah }\end{array}$ & $\begin{array}{l}\text { Tidak ada aktivitas penebangan } \\
\text { liar didalam kawasan hutan desa. }\end{array}$ & $\begin{array}{l}\text { Status hutan desa Labbo } \\
\text { merupakan hutan lindung }\end{array}$ \\
\hline
\end{tabular}

Dari hasil penelitian di lapangan, jika dibandingkan dengan kriteria active forest management yang diadopsi dari penelitian Yadav dkk (2003), saya mengkritisi bahwa penelitian Yadav dapat berlaku untuk pengelolaan hutan produksi yang mengelola kayu. Namun dalam kondisi dan status kawasan hutan lindung, Hutan Desa Labbo juga memenuhi semua kriteria active forest management dalam pengimplementasiannya. Oleh karena itu, pengelolaan Hutan Desa Labbo terkategori sebagai active management.

\subsection{Identifikasi aktor yang mendapat keuntungan pada pengelolaan hollow management dan aktor yang dirugikan} pada pengelolaan active management

Posisi kepala desa bukan lagi sebagai komisaris, melainkan sebagai pembina. Awalnya, kepala desa yang ditunjuk sebagai komisaris bertugas mengawasi seluruh kegiatan BUMDes yang kemudian dipertanggungjawabkan kepada kepala desa dan masyarakat. Namun sekarang, kepala desa menjadi pembina karena BUMDes telah masuk dalam program desa sehingga pihak desa yang mempertanggungjawabkan seluruh kegiatan BUMDes kepada masyarakat.

Peran kepala desa sebagai pembina sebenarnya sangat membantu dalam menjalankan kegiatan BUMDes. Namun kepala desa yang menjabat saat ini lebih cenderung mengutamakan untuk terlebih dahulu membangun infrastruktur/akses jalan menuju Hutan Desa dengan alasan agar memudahkan petani mengeluarkan hasil hutannya dan mengesampingkan program kerja/kegiatan BUMDes. Dari hal ini dapat dilihat bahwa ekistensi/power kepala desa ditunjukkan dengan menjanjikan rencana pembangunan infrastruktur di Hutan Desa. 
Sementara di sisi lain, LSM (Lembaga Swadaya Masyarakat) Balang Institute yang memfasilitasi pembangunan hutan Desa Labbo belum sepenuhnya sepakat dengan keputusan kepala desa yang menjabat saat ini karena masih fokus dalam pembangunan infrastruktur/akses menuju Hutan Desa dan belum dapat mengambil kebijakan yang tepat untuk mempertahankan eksistensi pengelolaan hutan Desa Labbo yang dulunya sempat menjadi icon percontohan skim pengelolaan kehutanan.

\section{KESIMPULAN}

Adapun hasil dari penelitian yang didapatkan di lapangan, maka dapat ditarik kesimpulan bahwa :

1. Analisis yang dilakukan untuk melihat tingkat keaktifan pengelolaan dari aspek produksi, distribusi dan institusi, dapat dilihat bahwa yang terealisasi di lapangan jika dipersenkan sebanyak 25,19\% dan yang tidak terealisasi di lapangan jika dipersenkan sebanyak $41,20 \%$. Angka diatas tidak bisa membandingkan tinggi rendahnya / penting tidaknya salah satu unsur (produksi, distribusi, institusi), karena unsur-unsur yang diteliti setara. Pengelolaan hutan Desa Labbo termasuk dalam kategori active management. Karena dari hasil analisis dokumen dan observasi di lapangan, kinerja dapat dikatakan aktif apabila rencana dan implementasi tercapai. Dan angka diatas menunjukkan bahwa rencana yang telah dibuat dalam pembangunan Hutan Desa Labbo sangat baik, tetapi pengimplementasiannya tidak sepenuhnya terealisasi karena terdapat kondisi-kondisi tertentu yang tidak dapat dilakukan baik dari pengurus BUMDes maupun dari masyarakat setempat ataupun kondisi lapangan yang tidak memungkinkan (status kawasan hutan lindung).

2. Analisis mengenai aktor yang diuntungkan dalam status hollow management pada Hutan Desa Labbo yaitu adanya ekistensi/power dari kepala desa yang ditunjukkan dengan menjanjikan masyarakat Desa Labbo pembangunan infrastruktur/akses menuju Hutan Desa. Sedangkan pada kondisi active management, LSM Balang Institute belum sepenuhnya sepakat dengan keputusan kepala desa yang menjabat saat ini karena masih fokus dalam pembangunan infrastruktur/akses menuju Hutan Desa dan belum dapat mengambil kebijakan yang tepat untuk mempertahankan eksistensi pengelolaan Hutan Desa Labbo.

\section{DAFTAR PUSTAKA}

Bachri, B. S. 2010. Meyakinkan Validitas Data Melalui Triangulasi pada Penelitian Kualitatif. Jurnal Teknologi Pendidikan, 10(1), 46-62.

Dokumen Rencana Kerja Hutan Desa Labbo Tahun 2010-2030, Kabupaten Bantaeng, Provinsi Sulawesi Selatan

Dokumen Rencana Tahunan Hutan Desa Labbo, Kabupaten Bantaeng, Provinsi Sulawesi Selatan

Muin, Nurhaedah dan Evita Hapsari.2014. Hutan Desa Kabupaten Bantaeng dan Manfaatnya Bagi Masyarakat. Makassar. Balai penelitian kehutanan Makassar

Munks, S. A., Koch, A. J., \& Wapstra, M. 2009. From Guiding Principles for the Conservation of Forest Biodiversity to on-Ground Practice: Lessons from Tree Hollow Management in Tasmania. Forest Ecology and Management, 258(4), 516-524.

Nasution, S. 2001. Metode Penelitian. Jakarta: Sinar Harapan.

Ningrum, wiwin Y. 2011. Kajian Penguatan Kelembagaan BUMDes dalam Pengelolaan Hutan Desa di Desa Labbo Kecamatan Tompobulu Kabupaten Bantaeng. Makassar. Fakultas Kehutanan Unhas

Nurdiani, N. 2014. Teknik Sampling Snowball Dalam Penelitian Lapangan. Jurnal ComTech, 5(02).

Nurdiansyah, I.M. 2013. Hak Pengusahaan Hutan. .http://miqbalnurdiansyah.blogspot.co.id/2013/07/hph.html Diakses tanggal 03 November 2016. 
Pedoman Pengelolaan Hutan Desa Labbo No. 01/BMDs-GT/LB/KTB/I/2010, Desa Labbo, Kabupaten Bantaeng, Provinsi Sulawesi Selatan

Peraturan Desa Labbo No.02 Tahun 2010 tentang Lembaga Pengelolaan Hutan Desa Labbo, Kabupaten Bantaeng, Provinsi Sulawesi Selatan

Priantara, D. 2012. Studi Empiris Pengungkapan Sukarela Kinerja Sosial Perusahaan Di Bidang Lingkungan Hidup Oleh Perusahaan Terbuka. Universitas Tarumanegara

Raditya, A. N. 2012. Analisis Faktor-Faktor yang Mempengaruhi Tingkat Pengungkapan Islamic Social Reporting (ISR) pada Perusahaan yang Masuk Daftar Efek Syariah (DES). Skripsi. Jakarta: Fakultas Ekonomi Universitas Indonesia.

Santosa, A., Santoso, H., Sahide, M.A.K., Lisanawati, \& Alloy, S. 2011. Status Kehutanan Masyarakat di Indonesia. Jurnal Kehutanan Masyarakat Vol.3 No. 1 Tahun 2011. Bogor. FKKM

Singh, S., \& Khare, A. 2016. People's Participation in Forest Management. The Commonwealth Forestry Review, 279-283.

Smith, A. P., \& Lindenmayer, D. 1988. Tree Hollow Requirements of Leadbeater's Possum and Other Possums and Gliders in Timber Production Ash Forests of The Victorian Central Highlands. Wildlife Research, 15(4), 347-362.

Stephens, S. L., \& Ruth, L. W. 2005. FEDERAL FOREST-FIRE POLICY IN THE UNITED STATES. Ecological applications, 15(2), 532-542.

Supratman dan Sahide, M.A.K. 2010. Pembangunan Hutan Desa di Kabupaten Bantaeng: Konsep, Proses, dan Refleksi. Makassar. RECOFTC

Supratman. 2012. Reformasi Managemen Hutan. Makassar. P3i Press

Supratman dan Sahide M.A.K. 2013. Hutan Desa dan Pembangunan Sosial Ekonomi Masyarakat Desa di Kabupaten Bantaeng. Jakarta

Surat Keputusan Gubernur Sulawesi Selatan No.3805/XI/TH 2010 tentang Pemberian Hak Pengelolaan Hutan Desa di Kawasan Lindung Seluas 342 Hektar Kepada Badan Usaha Milik Desa (BUMDes) Ganting Desa Labbo, Kecamatan Tompobulu, Kabupaten Bantaeng, Provinsi Sulawesi Selatan.

Surat Keputusan Menteri Kehutanan No.55/Manhut-II/2010 tentang Penetapan Kawasan Hutan sebagai Areal Kerja Hutan Desa pada Hutan Lindung Seluas 342 Hektar Terletak dalam Wilayah Administrasi Desa Labbo, Kecamatan Tompobulu, Kabupaten Bantaeng, Provinsi Sulawesi Selatan.

Yadav, N. P., Dev, O. P., Springate-Baginski, O., \& Soussan, J. 2003. Forest Management and Utilization Under Community Forestry. Journal of Forest and Livelihood, 3(1), 37-50.

Yusran, 2012. Hutan dan Masyarakat : Tinjauan dalam Perspektif Kebijakan dan Sosial Ekonomi. Bogor. UHP dan IPB Press. 